\title{
Calculation method for the service life of Chinese historical reinforced concrete buildings
}

\author{
Hui Jin ${ }^{1}$, and Qing Chun, ${ }^{1, *}$ \\ ${ }^{1}$ School of Architecture, Southeast University, 2 Sipailou Road, Nanjing 210096, China
}

\begin{abstract}
Almost all of the existed studies on the corrosion of rebars were based on round-section rebars. However, the square-section steel rebars were widely used in China from 1912 to 1949, and there was no specific calculation model or durability assessment method for this type of historical buildings. In this study, based on the original configuration design of this kind of structures, the experiments of the corrosion-induced cover cracking of a certain number of reinforced concrete members with square-section rebars were carried out with the electrochemical acceleration method. The average rust depths of the square-section rebars at the critical corrosion-induced cover cracking moment were obtained. Then, the calculation method of critical rust depth of steel rebars at the concrete cover cracking moment was presented with data fitting method. Finally, combining with predication of carbonization life of concrete, a calculation method of the service life for Chinese historical RC buildings using square-section rebars was proposed. The research results can provide the basis for the durability assessment and conservation for Chinese historical RC buildings.
\end{abstract}

\section{Introduction}

The corrosion of the steel rebar within concrete is one of the major deterioration problems for the durability of reinforced concrete structures [1]. For the evaluation of durability, the time for the repair and maintenance for the reinforced concrete (RC) structures is usually determined by the appearance of the corrosion-induced cover cracking. Many studies have proposed calculation models to predict the time of crack initiation, including laboratory tests and on-site investigations [1-3] and theoretical models [4, 5]. However, all of these experiments and prediction models were for round-section rebars, and there is no prediction model for square-section rebar case. Actually, the square-section rebars were widely used for RC buildings in China from 1912 to 1949 [6], and the majority of the RC buildings had been listed as protective historical buildings. The square-section and round-section are mechanically different, and thus the existed theoretical models and calculation models are not suitable for these building that using the square-section rebars. The suitable calculation method for the service life of this kind of RC structure is urgently demanded and necessary. The type of square-section rebars are shown in Fig. 1.

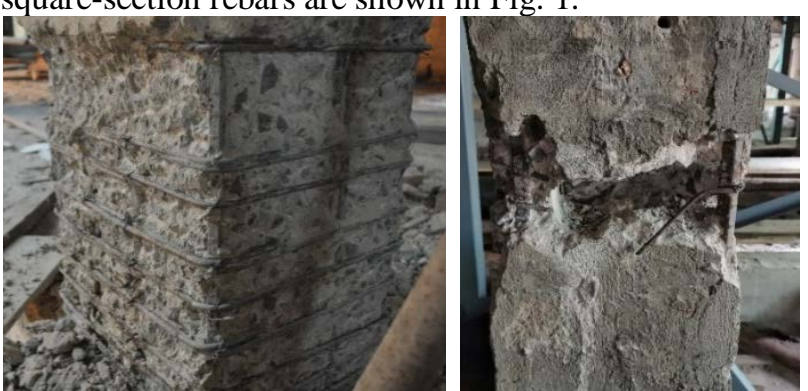

Fig. 1. The square-section rebars form historical RC buildings. The research on the RC structures that using square-section rebars is scarce. Chun and Pan [6] proposed a modified model for calculating the durability and carbonation life for Chinese modern RC structures. The calculation models were a modification of existed calculation models for round-section rebars, while the use of square-section rebars was not token account especially. Chun et al. [7] tested 66 rebars including 36 square-section rebars 30 round-section rebars from several Chinese modern RC structures built from 1912 to 1949 and presented the geometries, the physical and mechanical performance, the chemical composition and the metallographic of those rebars. Dong et al. [8] carried out an electrochemical accelerated corrosion for square-section rebars from the RC structures built in the Republic of China era with 8 specimens. The corrosion products were analyzed with X-ray diffraction, and the average value of the ratio of the critical corrosion depth and width of the squared rebar was presented, but they did not present a general calculation method.

In this study, an electrochemical accelerated corrosion experiment for square-section rebars was carried out, and an empirical calculation method for the critical corrosion depth of square-section rebars was presented through the fitting data method. Eventually, a suitable service life calculation method for the RC structures which using square-section rebars was proposed.

\section{The existed calculation method of service-life of RC structures}

In this study, the time of concrete cover cracking due to corrosion was taken as the service life of this type of RC structure. The service life included the period before corrosion which is called carbonization life and the period of cover cracking due to corrosion.

\footnotetext{
* Corresponding author: cqnj1979@163.com
} 


\subsection{Carbonization life}

The Chinese national standard GB/T 51355 Standard for durability assessment of existing concrete structures [9] has been widely accepted for the durability evaluation of the RC structures in China. Due to the lack of the study on the water-cement ratio and the cement dosage per unit volume for the RC structures built from 1912 to 1949, the recommended method of calculating carbonization life in GB/T 51355 [9] was adopted in this paper. The calculation method is depended on the in-situ test for a RC building, which can reduce the influence of the quality of the material and the different prescriptions of materials. The equation is as following

$$
t_{i}=15.2 K_{k} K_{c} K_{m}
$$

where $t_{i}$ is the carbonization life of the concrete (a); $K_{k}$ is the impact coefficient of concrete carbonation, which is depended by carbonation factor, $k=x_{c} / \sqrt{t_{0}}$, $x_{c}$ is the measured carbonization depth (mm), and $t_{0}$ is the service time of the structure until the test; $K_{c}$ is the impact coefficient of cover depth; and $K_{m}$ is the impact coefficient of location of the rebar, on corner or not.

\subsection{Service life}

The critical time of the cover cracking due to corrosion is depended on the critical corrosion depth of the rebar and the rate of corrosion. The equations for calculating service life of RC structures in GB/T 51355 [9] are as following:

$$
\begin{gathered}
t_{c r}=t_{i}+\frac{\delta_{c r}}{\lambda} \\
\lambda=5.92 k_{c l}(0.75+0.0125 T)(R H- \\
0.50)^{2 / 3} c^{-0.675} f_{c u, k}-1.8 \\
\delta_{c r}=0.012 c / d+0.00084 f_{c u, k}+0.018
\end{gathered}
$$

where $\delta_{c r}$ is the critical corrosion of rebar (mm); $\lambda$ is the rate of rebar corrosion $(\mathrm{mm} / \mathrm{a}) ; k_{c l}$ is the rebar location coefficient, which is 1.6 for rebar on corner, or 1.0; $c$ is the cover depth $(\mathrm{mm}) ; f_{c u, k}$ is the standard value of concrete compressive strength (MPa); $T$ is the average environment temperature $\left({ }^{\circ} \mathrm{C}\right) ; R H$ is the environment humidity (\%); and $t_{c r}$ is the service life (a).

The corrosion rate can be thought the same for the square-section rebars and round-section rebars, thus, the Eq. (3) is adopted in this study. Mechanically, square section and round section are totally different, resulting in the different type of compression from the corrosion on the concrete. Thus, the critical depths of rust are also different for these two types of rebars. The key part of this study is to modify the Eq. (4).

\section{Corrosion-induced cover cracking experiments for square-section steel rebars}

\subsection{The materials and experiment}

The accelerated corrosion experiments included ten specimens and all the squared rebars were collected from abandoned components of the historical RC buildings in China. All the rebars were undeformed and the surface rust was removed by polishing, which is shown in Fig. 2. The widths of the rebars included $16 \mathrm{~mm}$ and $22 \mathrm{~mm}$. According to the historic book [10], the contents and volume ratios were Cement: Sand: Stone (Coarse aggregate) $=1: 2: 4$, and the water was accounted for $10 \%$ $\sim 13 \%$ weight of all contents. The aimed compressive strength of the concrete specimens after 28-day curing was $15 \mathrm{MPa}[6,8]$, and the averaged compressive strength (three specimens) of the standard $150 \mathrm{~mm}$ cube was 15.6MPa after curing. The dimension of the specimens was $150 \mathrm{~mm} \times 200 \mathrm{~mm} \times 150 \mathrm{~mm}$, and the steel rebar was a little longer than the width of the concrete specimen for the manufacture of the specimens. The general design depth of concrete cover at that period was 38mm [10], and the cover depths for the specimens were $36 \mathrm{~mm}, 38 \mathrm{~mm}$, $40 \mathrm{~mm}, 42 \mathrm{~mm}$ and $44 \mathrm{~mm}$. The dimension and the diagrammatic sketch of the specimen are shown by Fig. 3 .

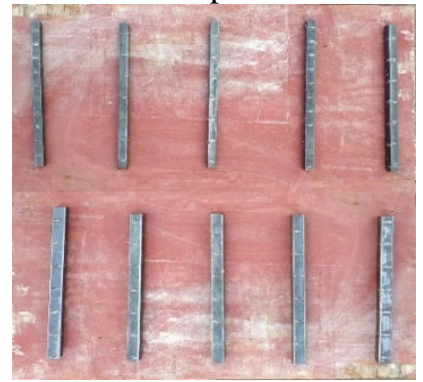

Fig. 2. The experimental squared rebars after rust removal.

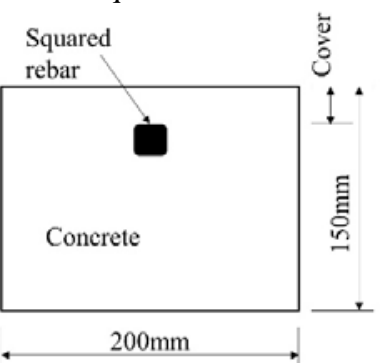

Fig. 3. Dimension of the specimen.

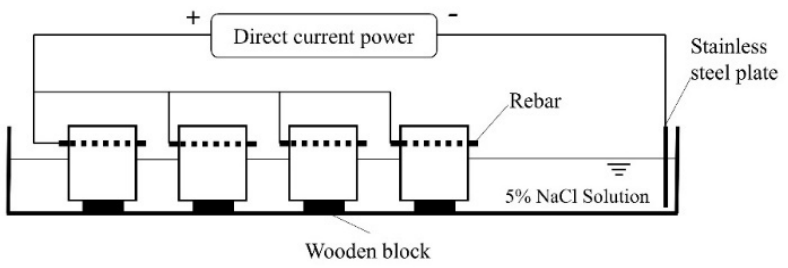

Fig. 4. Schematic diagram of electrochemical accelerated corrosion test with the method of parallel circuit.

The accelerated corrosion for steel rebars was achieved by impressed direct current, and the value was $100 \mu \mathrm{A} / \mathrm{cm}^{2}[1,5]$. The electrolyte solution was $5 \% \mathrm{NaCl}$ solution [1,5], and half of the specimens were immersed in the solution upon the wooden heel blocks. After the 
welding of the electric wires on the rebars, the side surfaces and the external rebars were coated with epoxy resin, approximately $2 \mathrm{~mm}$. After the solidification of the epoxy resin and before the impression of the direct current, the experimental specimens were immersed in the solution for 72 hours, to make sure that the specimens were in a wet state before electrifying. Finally, the test ended when the width of the cover crack achieved $0.1 \mathrm{~mm}$ [9]. The schematic diagram of the electrochemical accelerated corrosion for steel rebars is shown in Fig. 4.

\subsection{Results and discussions}

The detailed information of specimens is listed in Table 1, and the results of the experiments and the calculated results from other models as well. It is obvious that the calculation method for the critical rust depth of rebar from GB/T 51355 [9] was not adaptive for the square-section rebars. The value of the average error was about $29.3 \%$. And the calculated methods from Rodriguez et al. [11] and Zhang [12] were too conservative for the square-section rebars. The comparisons between calculated results and tests in Table 1 . It verified that the calculation methods for critical rust depth of round-section rebars were not suitable for the square-section rebar. The existed calculation methods are listed in Table 1. It can be found that the critical rust depth can be determined by the thickness of cover, the diameter of rebar, and the strength of the concrete. The main difference among these three models is the relevance between the strength of concrete and the critical rust depth. The strength of the concrete should be positively related to the cracking time in theory, so it should also be positively related to the critical rust depth of rebar. However, the strength of concrete is negatively related to the critical rust depth of rebar in the calculation methods from Rodriguez et al. and Zhang. Thus, the results from Rodriguez et al. and Zhang were relatively more erroneous. Although there is a positive constant in the calculation method from Rodriguez et al. to offset the theoretical error to some extent, it would still have relatively larger error once the ratio of cover depth and rebar diameter or the strength of concrete of the predicted target was over the range of the specimens in the original experiment.

Table 1. The information of the specimens and the results of the tests.

\begin{tabular}{|c|c|c|c|c|c|c|c|c|c|c|}
\hline \multirow{2}{*}{ Item } & \multirow{2}{*}{$\begin{array}{l}\text { Bar } \\
\text { width } \\
/ \mathrm{mm}\end{array}$} & \multirow{2}{*}{$\begin{array}{c}\text { Cover } \\
\text { depth } \\
/ \mathrm{mm}\end{array}$} & \multirow{2}{*}{$\begin{array}{l}\text { Compressiv } \\
\text { e strength } \\
\text { /MPa }\end{array}$} & \multicolumn{7}{|c|}{ Critical corrosion depth (mm) } \\
\hline & & & & $\begin{array}{c}\text { Test } \\
\text { value }\end{array}$ & $\begin{array}{c}\text { Calculated } \\
\text { value [9] }\end{array}$ & $\begin{array}{c}\text { Error/ } \\
\%\end{array}$ & $\begin{array}{c}\text { Calculated } \\
\text { value [11] }\end{array}$ & $\begin{array}{c}\text { Error/ } \\
\%\end{array}$ & $\begin{array}{c}\text { Calculated } \\
\text { value [13] }\end{array}$ & $\begin{array}{c}\text { Error/ } \\
\%\end{array}$ \\
\hline A-1 & 16 & 36 & 14.7 & 0.0641 & 0.0573 & -10.6 & 0.0182 & -71.6 & 0.0186 & -71.0 \\
\hline A-2 & 16 & 38 & 14.9 & 0.0900 & 0.0590 & -34.4 & 0.0186 & -79.4 & 0.0197 & -78.1 \\
\hline A-3 & 16 & 40 & 15.6 & 0.1093 & 0.0611 & -44.1 & 0.0176 & -83.9 & 0.0211 & -80.7 \\
\hline A-4 & 16 & 42 & 15.8 & 0.0951 & 0.0628 & -34.0 & 0.0180 & -81.1 & 0.0222 & -76.7 \\
\hline A-5 & 16 & 44 & 15.2 & 0.1134 & 0.0638 & -43.8 & 0.0205 & -81.9 & 0.0229 & -79.8 \\
\hline B-1 & 22 & 36 & 14.3 & 0.0639 & 0.0496 & -22.3 & 0.0148 & -76.9 & 0.0135 & -78.9 \\
\hline B-2 & 22 & 38 & 14.8 & 0.0652 & 0.0512 & -21.6 & 0.0141 & -78.5 & 0.0145 & -77.8 \\
\hline B-3 & 22 & 40 & 15.6 & 0.0673 & 0.0529 & -21.4 & 0.0125 & -81.4 & 0.0156 & -76.8 \\
\hline B-4 & 22 & 42 & 16.2 & 0.0715 & 0.0545 & -23.8 & 0.0116 & -83.7 & 0.0167 & -76.7 \\
\hline B-5 & 22 & 44 & 14.7 & 0.0860 & 0.0543 & -36.8 & 0.0163 & -81.0 & 0.0166 & -80.7 \\
\hline
\end{tabular}

Note: The values of the compressive strength were tested by crushing the specimens when the width of the crack reached $0.1 \mathrm{~mm}$. Error $=($ calculated value - test value $) /$ test value $* 100 \%$.

Table 2. Calculation methods of critical rust depth of round-section rebars.

\begin{tabular}{ll}
\hline \multicolumn{1}{c}{ Literature origin } & Calculation methods \\
\hline GB/T 51355 [9] & $\delta_{c r}=0.012 c / d+0.00084 f_{c u, e}+0.018$ \\
Rodriguez et al. [11] & $\delta_{c r}=0.0074 c / d-0.0226 f_{c k}+0.0838$ \\
Webster and Clark [13] & $\delta_{c r}=0.00125 c$ \\
Zhang [12] & $\delta_{c r}=0.008 c / d-0.00055 f_{c k}-0.0075$ \\
\hline
\end{tabular}

\section{The calculation method of the critical rust depth of square-section rebars at cover cracking time}

It can be observed that the ratio of cover depth and rebar diameter was accepted by the majority of the studies. For the strength of concrete, Rodriguez et al. [11] adopted the tensile strength of the concrete while GB/T 51355 [9] and Zhang [13] adopted the compressive strength of the concrete. However, according to some studies on the theoretical models for the problem about the cover cracking due to corrosion $[4,5]$, it should be the tensile strength of the concrete that determine the critical cracking of the cover directly. Thus, the tensile strength of concrete was adopted in this study for the new empirical formulas. Although it is hard to obtain the tensile strength of concrete for in-situ testing for existed RC structures, the tensile strength of concrete can be calculated through the relationship $f_{t}=0.85 \sqrt{f_{\text {cue } e}}$ [14]. Then, the calculation method for the critical depth of square-section rebars is as following:

$$
\delta_{c r}=0.0409 c / d^{x}+0.0088 f_{t k}-0.0348
$$

where $d^{\prime}$ is the width of the square-section rebar, and $f_{t k}$ is the tensile strength of concrete. The formula was obtained by the 10 tested specimens with 10 data, and the 
fitting method was least squares. The coefficient of determination for this fitting formula was 0.7374 . Yu et al. [15] calculated the coefficients of determination for some other similar formulas, which are listed in Table 3. It can be found that the coefficients of determination of the presented empirical formulas is much larger than other similar empirical formulas for round-section rebars. The coefficient of determination verified the accuracy of the fitting formula for this problem, and the empirical formula should be qualified for the engineering application. Based on the coefficients of environmental factors and location factors recommended in GB/T 51355 [9], Eq.(1-3) and Eq. (5) consists of the prediction model of service life for RC buildings using square-section steel rebars.

Table 3. The coefficients of determination for different calculation models [15].

\begin{tabular}{cc}
\hline Calculation models & Coefficients of determination $R^{2}$ \\
\hline Rodriguez et al. & 0.6450 \\
Webster and Clark & 0.6051 \\
Zhang & 0.6450 \\
\hline
\end{tabular}

\section{Conclusions and discussions}

The square-section steel rebars were widely used for RC buildings in China from 1912 to 1949 . To obtain a suitable method to predict the service life of the type of historical buildings, an electrochemical accelerated corrosion experiment for square-section rebars was carried out. Through data fitting method, an empirical calculation method of the critical corrosion depth of square-section rebars at the corrosion-induced cover cracking moment was obtained. It was found that the existed calculation methods for round-section rebar cases were not suitable for square-section rebar cases. Combining with the predicted calculation method of carbonization life of concrete, a method of predicting the service life for the historic RC buildings using square-section rebars was proposed.

However, the empirical formula in this study was established on limited number of specimens as the difficulties of collecting the real historical square-section. Thus, it is recommended for the further experiment to include more specimens and the strengths of the concrete should be varied in a lager range. Besides, the theoretical model of corrosion-induced cover cracking is also required in the future research.

\section{Acknowledgments}

The financial supports of the Jiangsu Provincial Key Research and Development Plan (BE2017717) and Jiangsu Province Cultural Relics Research Programs (2017SK02) are greatly acknowledged.

\section{Reference}

1. K. Vu, M.G. Stewart, J. Mullard, Corrosion-induced cracking: Experimental data and predictive models. Aci Structural Journal, 102, 5: 719-726 (2005)
2. C. Andrade, Alonso C and Molina F J 1993 Cover cracking as a function of bar corrosion .1. experimental test Materials and Structures 26: 453-464 (1993)

3. C. Lu, S. Yuan, R. Liu, Experimental and probabilistic analysis of time to corrosion-induced cover cracking for marine reinforced concrete structures Corrosion Engineering, Science and Technology 52: 124-133 (2017)

4. T. EI Maaddawy, K. Soudki, A model for prediction of time from corrosion initiation to corrosion cracking Cement and Concrete Composites 29: 168-175 (2007)

5. C. Lu, W.L. Jin, and R.G. Liu, Reinforcement corrosion-induced cover cracking and its time prediction for reinforced concrete structures Corrosion Science 53: 1337-1347 (2011)

6. Q. Chun, J. W. Pan, Research on the methods for calculation and prediction of the service life of reinforced concrete buildings built during the period of the Republic of China in Jiangsu and Zhejiang provinces Sciences of Conservation and Archaeology 26: 29-33 (2014)

7. Q. Chun, K. Von Balen, J. W.Pan, Experimental research on physical and mechanical performance of steel rebars in Chinese modern reinforced concrete buildings built during the Republic of China era from 1912 to 1949 Materials and Structures 49: 3679-3692 (2015)

8. Y. H. Dong, Q.Chun, X. B Xu., J. G.Wang, S. Huang, Critical corrosion depth of rebar of Republican Period reinforced concrete structures, Journal of Zhejiang University (Engineering Science) 51: 27-37 (2017)

9. Ministry of Housing and Urban-Rural Development of the People's Republic of China(MOHURD) \&State Administration for Market Regulation, GB/T 51355 Standard for durability assessment of existing concrete structures (Architecture Publishing \& Media Co., Ltd., Beijing 2019)

10. J. Zhang, Simplified reinforced concrete design method(World Bookstore, Shanghai 1929)

11. J. Rodriguez, L. M. Ortega, J. Casal, J. M. Diez, Corrosion of reinforcement and service life of concrete structures Durability of Building Materials and Components 1: 117-126 (1996)

12. W. P. Zhang, Corrosion damage prediction and durability evaluation of reinforced concrete structures (Tongji University, 1999)

13. M. Webste, L. Clark, The structural effects of corrosion - an overview of the mechanisms, Conference: Concrete Communications Conference at University of Birmingham (2000)

14. F. Legeron, P. Paultre, Prediction of modulus of rupture of concrete Aci Materials Journal 97: 193-200 (2000)

15. M. X. Yu, S. L. Li, S. H. Zhang,N. S. Qiang, Model for calcualting the steel corrosion depth based on crack width, Concrete, 301: 11-23 (2014) 